\title{
ANÁliSE DA PRODUÇÃO DE PROTEASE E LIPASE POR FUNGOS FILAMENTOSOS ISOLADOS DO FRUTO DA MACAÚBA (ACROCOMIA ACULEATA (JACQ) LOOD. EX MART)
}

\author{
C. S. NASCIMENTO ${ }^{1}$, V.L. dos SANTOS $^{2}$ e M.H.C. ANDRADE ${ }^{1}$ \\ ${ }^{1}$ Universidade Federal de Minas Gerais, Departamento de Engenharia Química \\ ${ }^{2}$ Universidade Federal de Minas Gerais, Departamento de Microbiologia \\ E-mail para contato: mila_salesnasc@ hotmail.com
}

\begin{abstract}
RESUMO - A palmeira macaúba produz frutos com elevado potencial de produtividade em óleo, o estudo de micro-organismos associados a frutos como os da palmeira macaúba permite o entendimento do papel dos mesmos na promoção do crescimento da planta, deterioração dos frutos, além de serem explorados como fonte potencial de produção de enzimas hidrolíticas. $\mathrm{O}$ objetivo do trabalho foi avaliar a produção qualitativa e quantitativa de lipases e proteases por fungos filamentosos isolados de frutos da macaúba. A produção de enzimas lipases e proteases de 19 isolados foi avaliada por meio da detecção da formação de halos de hidrólise após crescimento em meio de cultura sólido emulsionado com óleo de oliva e de caseína, respectivamente. Quatro isolados apresentaram atividade lipolítica e 16 proteolítica. Os dezenove isolados também foram avaliados em ensaios quantitativos de produção de enzimas em meio líquido adicionados dos substratos de enzimas, óleo de oliva e caseína. Na avaliação da atividade lipolítica utilizando os sobrenadantes das culturas e o método do pNPP, os morfotipos M233, M184, M62 apresentaram atividade, sendo a máxima de 2,684 U/mL para o isolado M62. Nos ensaios de produção de proteases, avaliada pela hidrolise de azocaseína, 19 morfotipos apresentaram atividade, sendo a atividade máxima para o morfotipo M27 de $5,417 \mathrm{U} / \mathrm{mL}$. Este trabalho confirma a importância de fungos filamentosos isolados dos frutos da macaúba como potenciais produtores de enzimas de interesse biotecnológico.
\end{abstract}

\section{INTRODUÇÃO}

A Macaúba (Acrocomia aculeata (Jacq.) Lodd. ex Mart.) é uma palmeira frutífera, nativa de florestas tropicais e com ampla distribuição geográfica. No Brasil ocorre nos estados do Ceará, Minas Gerais, Mato Grosso, Mato Grosso do Sul, São Paulo e por toda região sul. Esta palmeira é altamente resistente a pragas e variações de temperatura, crescendo, inclusive, em áreas com baixo índice pluviométrico (Lorenzi et al., 2004).

Essa espécie apresenta ampla utilidade e, mais recentemente, seu fruto tem despertado grande interesse econômico principalmente pelo elevado potencial de produtividade em óleo de até $6000 \mathrm{~kg} . h a$. Em meio as suas várias utilidades são relatadas usos medicinais, alimentícios, cosméticos, entre outros. Adicionalmente, relata-se que a instalação de plantios racionais e de programas de melhoramento podem viabilizar a produção em escala industrial de biodiesel a partir desta palmeira (Lorenzi, 2006).

O maior desafio hoje é transformar a atual atividade extrativista em cultivos comerciais, que permitam à exploração sustentável desta palmeira. A falta de informações a respeito do ponto de coleta de seus frutos, assim como da duração de seus períodos de permanência no solo e em 
estocagem, bem como de sua microbiota associada, podem ser considerados como alguns dos problemas do extrativismo atual da espécie. A degradação das polpas pela ação de enzimas microbianas resulta em um óleo com altos níveis de acidez, inviável para indústria.

O estudo das comunidades micro-organismos associados aos seus frutos, assim como das relações ecológicas desenvolvidas entre estas espécies, ajuda a estabelecer critérios de manejo adequados durante todas as fases do processamento da macaúba. Outra justificativa para um esforço integrado de prospecção tecnológica da biodiversidade microbiana associada a palmeira é a obtenção de linhagens produtoras de enzimas hidrolíticas extracelulares (lipase, pectinase, celulase, celulase, xilanase, amilase, protease), que já apresentam grande interesse industrial, e de acordo com estudos recentes, importantes de grande utilidade na extração enzimática de óleos vegetais em escala comercial.

Nas últimas décadas, a utilização de fungos em bioprocessos ganhou importância devido à produção de enzimas com características físico-químicas variadas, potencial de produção em grande escala, e a capacidade de secretar as enzimas produzidas para o meio extracelular. (Papagianni, 2004). Entre as enzimas microbianas com ampla aplicação biotecnológica destacamse as lipases e proteases.

Lipases (triacil glicerol éster hidrolases, EC 3.1.1.3) são enzimas conhecidas como carboxilesterases que catalisam reações químicas com acilgliceróis a partir de uma estrutura de trioleilglicerol, liberando mono ou digliceróis, ácidos graxos e glicerol (Jaeger e Eggert, 2002). Contudo essas biomoléculas podem também catalisar reações inversas na ausência de água esterificação e as distintas reações de transesterificação (Freire, 2008). As lipases se destacam entre as hidrolases devido as suas múltiplas aplicações, sendo utilizadas nas indústrias de detergentes, medicamentos, alimentos, têxteis, polpa e papel, curtumes, cosméticos, biodiesel, biossensores e também no tratamento de efluentes (Houde et al., 2004; Hasan et al., 2006)

Proteases são enzimas capazes de quebrar ligações peptídicas de cadeias protéicas. Estão amplamente distribuídas na natureza e estão associadas a importantes processos biológicos tais como: a digestão protéica, coagulação sanguínea e morte celular. As enzimas proteolíticas possuem também uma vasta aplicação comercial e industrial, estando entre os três maiores grupos de enzimas industriais (Romero et al., 2001). Estas enzimas são amplamente utilizadas na indústria de detergentes, couro, alimentos, química, tratamento de resíduos industriais e domésticos, medicamentos, cosméticos entre outras (Gupta et al., 2002).

O presente estudo teve como objetivo caracterizar isolados de fungos filamentosos de frutos de palmeiras Macaúba quanto à produção das exoenzimas de interesse industrial, lipases e proteases.

\section{METODOLOGIA}

O presente trabalho foi realizado no Laboratório de Desenvolvimento de Processos da Macaúba/DEQ e no Laboratório de Microbiologia Aplicada/ICB, da Universidade Federal de Minas Gerais (UFMG), MG. 


\subsection{Obtenção dos microrganismos}

Dezenove isolados de fungos filamentosos isolados de frutos da Macaúba (A. aculeata) cedidos pelo LMA- ICB-UFMG, foram utilizados no estudo.

\subsection{Ensaio Qualitativo: Screening para atividade enzimática}

Discos de $5 \mathrm{~mm}$ de diâmetro removidos das bordas de colônias crescidas por 4 dias em meio BDA, foram transferidos para placas de Petri contendo os meios específicos para detecção de produção das enzimas. Para detecção de lipases utilizou-se o meio de cultura descrito por Colen (2006) $\left[\left(\mathrm{NH}_{4}\right)_{2} \mathrm{SO}_{4} 0,5 \%,\left(\mathrm{NH}_{2}\right) \mathrm{CO} 0,2 \%, \mathrm{MgSO}_{4} 7 \mathrm{H}_{2} \mathrm{O} 0,1 \%, \mathrm{NaCl} 0,1 \%\right.$, sais biliares $0,2 \%$, extrato de levedura $0,05 \%$, ágar $1,5 \%$, óleo de oliva $1 \%$ ]. Para os ensaios para detecção de proteases utilizou-se o meio ágar Skim Milk. Os ensaios foram realizados em duplicata. As placas foram incubadas em BOD a $28^{\circ} \mathrm{C}$ por $72 \mathrm{~h}$ e produção da enzima evidenciada pela formação de uma zona clara em torno colônias.

\subsection{Ensaio Quantitativo: Produção de enzimas}

Os dezenove isolados de fungos filamentosos em estudo foram inoculados em meios líquidos de indução de produção de lipase e protease para quantificação da produção das enzimas.

Dois discos de micélio de $5 \mathrm{~mm}$ de diâmetro removidos das bordas de colônias crescidas por 4 dias em meio BDA, foram inoculados em frascos de vidro de $50 \mathrm{ml}$ contendo $10 \mathrm{~mL}$ do meio líquido de indução. Nos ensaios para a produção de Lipase utilizou-se o meio mineral $\left(\mathrm{NH}_{2} \mathrm{NO}_{3}\right.$ $0,1 \% ; \mathrm{KH}_{2} \mathrm{PO}_{4}$ 0,1\%; $\mathrm{MgSO}_{4} .7 \mathrm{H}_{2} \mathrm{O}$ 0,05\%; Peptona 2,0\%) adicionado de óleo de oliva $1 \%$ (v/v). Para os ensaios de produção de protease utilizou-se o meio YCB (Difco) suplementado com 0,01 $\%$ caseína e $0,1 \%$ glicose. Os frascos foram incubados a $28^{\circ} \mathrm{C}$ na rotação de $160 \mathrm{rpm}$ por até 7 dias. Alíquotas de $200 \mu 1$ foram retiradas em intervalos de 24 horas, e centrifugadas a $14.000 \mathrm{rpm}$ por 15 minutos. O sobrenadante obtido foi reservado para realização dos ensaios quantitativos de atividade enzimática. Os ensaios foram realizados em duplicata.

\subsection{Atividade Enzimática}

\section{$\underline{\text { Determinação da atividade lipolítica }}$}

A determinação da atividade da lipase foi realizada de acordo com metodologia descrita por Winkler e Stuckmann (1979), utilizando p-nitrofenilpalmitato (pNPP) como substrato. Uma unidade de atividade enzimática foi considerada como sendo a quantidade de enzima que catalisa a liberação de $1 \mu \mathrm{mol}$ de pNP por minuto nas condições do ensaio. Foi considerado um coeficiente de absorção molar do pNP igual a $1,275 \times 10^{4}$ mol. $\mathrm{L}^{-1} . \mathrm{cm}-1$. Os ensaios foram realizados em duplicata.

\section{Determinação da atividade proteolítica}

A atividade proteolítica foi determinada segundo a metodologia de Charney e Tomarelli (1947), utilizando a azocaseína como substrato e expressa em U/mL. Uma unidade de atividade da enzima foi definida como a quantidade da enzima necessária para produzir um 
aumento na absorbância igual a 0,01 por minuto de reação, nas condições de ensaio. Os ensaios enzimáticos foram realizados em duplicata.

\subsection{Estatística}

Análises de médias, desvio padrão, e regressões lineares para os cálculos de atividade enzimática $\left(\mathrm{R}^{2} \geq 95 \%\right)$ foram feitos utilizando o software Minitab version 16 .

\section{RESULTADOS E DISCUSSÃO}

\subsection{Screening para atividade de protease e lipase pelo método qualitativo}

Dezenove isolados de fungos filamentosos foram avaliados por seu potencial para produzir e secretar proteases e lipases, os resultados podem ser visualizados na Tabela 1. Destes morfotipos, $4(21,05 \%)$ foram positivos (presença de halo de hidrólise) para a secreção de lipases em meio de cultura sólido acrescido de azeite de oliva $1 \%$. Em relação a secreção de protease $14(73,68 \%)$ de fungos filamentosos foram positivos (presença de halo de hidrólise) para secreção de proteases quando cultivadas em ágar Skim milk.

Tabela 1 - Produção de lipases e proteases por fungos filamentosos isolados de frutos da palmeira macaúba evidenciada nos ensaios qualitativos

\begin{tabular}{cccccc}
\hline Morfotipo & Protease & Lipase & Morfotipo & Protease & Lipase \\
\hline M1 & + & - & M89 & + & - \\
\hline M8 & + & - & M109 & + & - \\
\hline M12 & + & + & M124 & + & - \\
\hline M19 & + & - & M162 & + & - \\
\hline M23 & + & + & M165 & - & - \\
\hline M26 & + & - & M184 & - & + \\
\hline M27 & + & - & M221 & + & + \\
\hline M29 & + & - & M233 & - & - \\
\hline M62 & - & - & M228 & + & - \\
\hline M70 & - & - & & & \\
\hline
\end{tabular}

A atividade enzimática não foi expressa pela relação entre os diâmetros do halo de hidrólise e do halo da colônia devido ao crescimento irregular dos fungos e consequente formação de halos disformes, que dificultou a mensuração de diâmetros.

\subsection{Atividade de protease e lipase pelo método quantitativo}

Nos ensaios de avaliação de produção de lipases em meio líquido, foi observado resultados positivos para os morfotipos M233, M184, M62. As atividades com o isolado em estudo e com a idade da cultura podem ser visualizadas na Figura 1. Os maiores valores foram observados após 144 horas de cultivo para os isolados M62 (2,684 U/mL) e M233 (1,386 $\mathrm{U} / \mathrm{mL}$ ), a partir do qual foi observado um decréscimo na atividade lipolítica. Por sua vez, o isolado M184 apresentou as menores atividades enzimáticas, sendo a atividade máxima 
$(0,866 \mathrm{U} / \mathrm{mL})$ observada no tempo de $72 \mathrm{~h}$. A produção de lipase iniciou-se no tempo de $24 \mathrm{~h}$ para o morfotipo M184 e no tempo de 72h para os morfotipos M233 e M62.

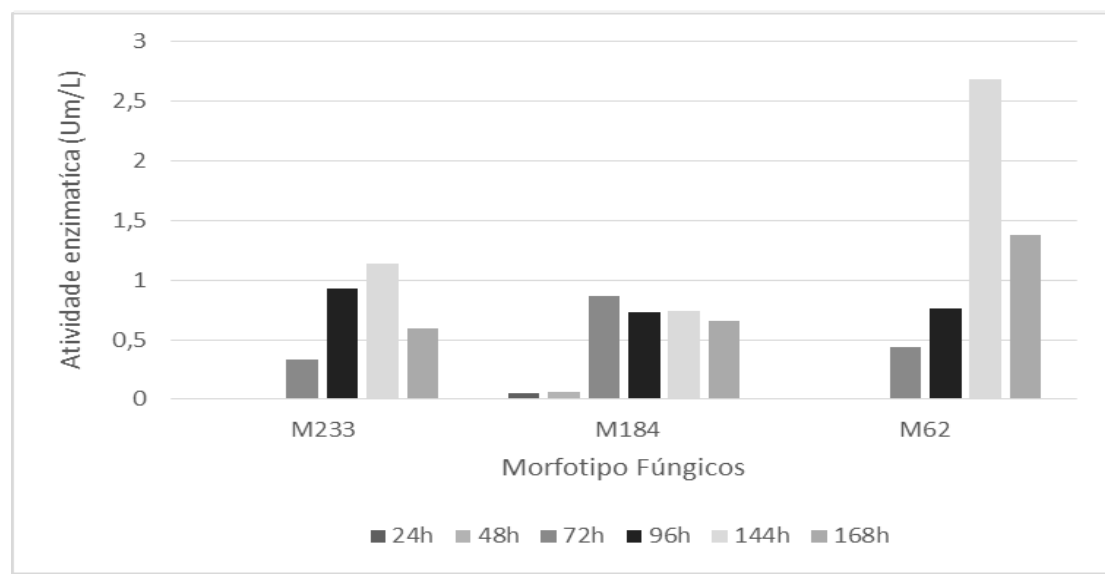

Figura 1: Atividade lipolítica dos morfotipos M233, M184, M62 isolados do fruto da macaúba

Verificou-se que os fungos com resultados positivos no ensaio qualitativo em meio de cultura sólido para detecção de lipase, M12, M23, M184, M221, apresentaram atividade negativa no ensaio quantitativo em meio de cultura líquido. Este resultado pode indicar que nestes isolados, as enzimas produzidas permanecem ligadas a parede celular, não sendo detectadas nos ensaios no meio de cultura líquido, que avalia atividade de eznima extracelular (Pérez-de-Moura et al., 2013). Outra possibilidade é que a condição de cultivo não favoreceu a produção da enzima. Diversos estudos tem mostrado que a produção de lipases pode ser afetada pelo tipo e concentração das fontes de carbono e nitrogênio, $\mathrm{pH}$ do meio, agitação, temperatura e concentração de oxigênio dissolvido no caso do bioprocesso submerso (Sharma, 2001; Colla et al., 2012; Colen, 2006.), ademais segundo Papagianni (2004), o sucesso na obtenção de um produto fúngico requer um conhecimento detalhado das características do crescimento e da fisiologia da cepa produtora, sendo cada fungo, único no seu desenvolvimento anatômico, morfológico e fisiológico. As diferenças entre eles ocorrem devido a algum fator que ao interferir no seu desenvolvimento provoca alterações que se traduzem em diferentes respostas àquele fator e cada um responde diferentemente.

Os morfotipos M233, M184, M62 apresentram resultado negativo no ensaio qualitativo em meio de cultura sólido para detecção de lipase e positivo no ensaio quantitativo em meio de cultura líquido. Este resultado sugere que estes morfotipos podem produzir lipases que apresentam maior habilidade de difusão no meio de cultura líquido, uma vez que a difusão da enzimas é influenciada pelo peso molecular da enzima, que pode a impedir de difundir pelo ágar e dessa forma, a atividade é considera como inexistente ou baixa (Silva, 2011).

\subsection{Determinação da atividade proteolítica pelo ensaio quantitativo}

A atividade em meio de cultura líquido foi positiva para todos os 19 morfotipos a partir do tempo de $24 \mathrm{~h}$ conforme demostra a Figura $2 \mathrm{a}$ e $2 \mathrm{~b}$. De forma geral, as atividades variaram com o isolado em estudo e com a idade da cultura. As maiores atividades foram observadas 
para os isolados M27, (5,4 U/mL), M23 (5,3U/mL), M109 (5,1 U/mL), M184 (4,7 U/mL), M19 (4,4 U/mL), M70(4,4 U/mL), M233 (4,3 U/mL) no tempo de 48 horas e M89 (4,9U/mL) no tempo de $144 \mathrm{~h}$. Os menores valores foram encontrados para os morfotipos M1 e M29 sendo de $0,08 \mathrm{U} / \mathrm{mL}$ e $0,09 \mathrm{U} / \mathrm{mL}$ respectivamente no tempo de 144 horas. Os morfotipos M1 e M26 apresentaram os menores valores de produção ao decorrer do tempo, sendo o morfotipo $\mathrm{M} 1$ a produção máxima de $1,3 \mathrm{U} / \mathrm{mL}$ em 72 horas e mínima de $0,08 \mathrm{U} / \mathrm{mL}$ e o morfotipo M26 com máxima de 0,3 U/mL em 48 horas e mínima de 0,1 U/mL em 72 horas.
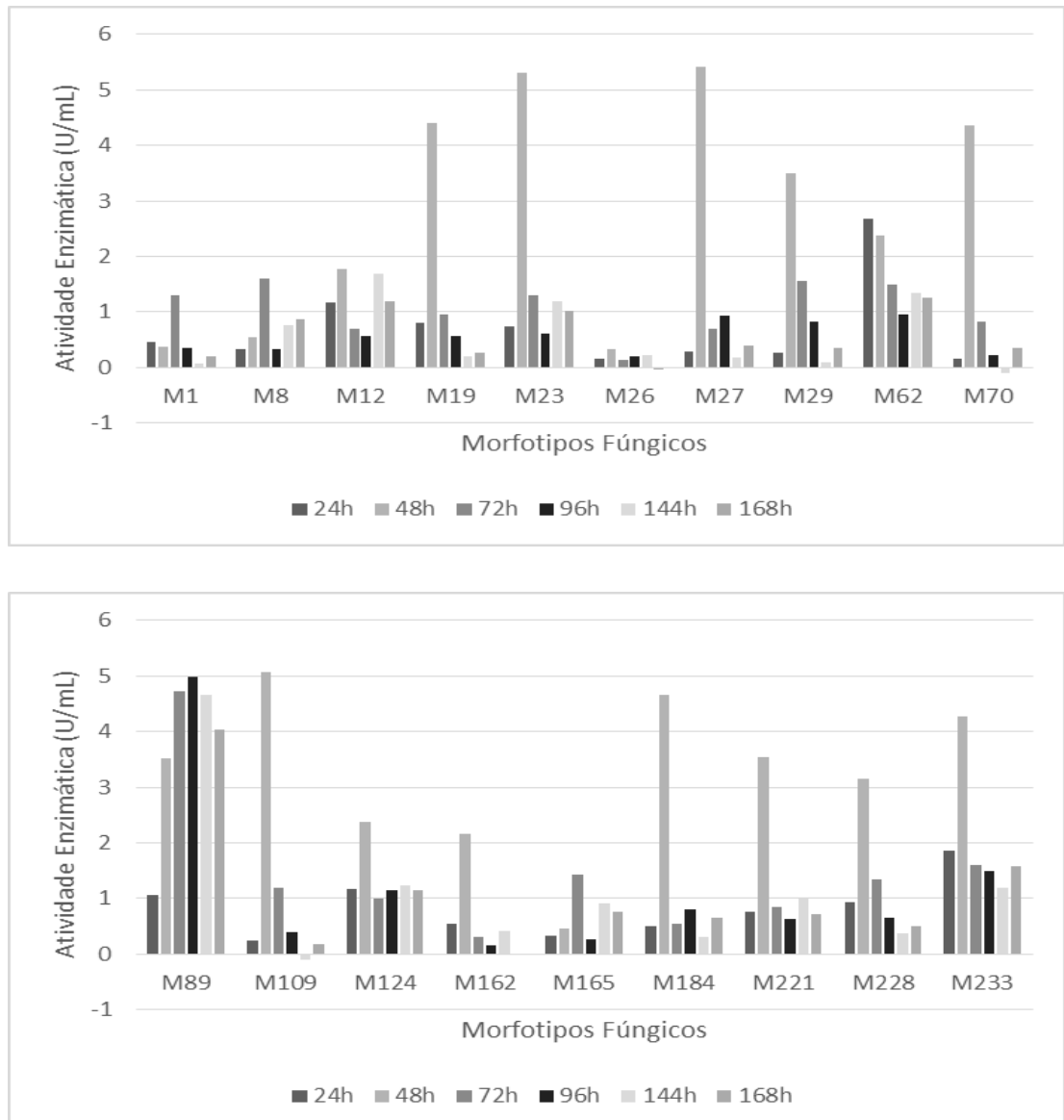

Figura 2 - Atividade proteolítica de fungos filamentosos isolados de frutos da palmeira Macaúba (a e b) .

Os isolados M62, M70, M165, M184 e M233 apresentaram resultado negativo no ensaio qualitativo em meio de cultura sólido para detecção de lipase e positivo no ensaio quantitativo em meio de cultura líquido, este resultado indica que estes morfotipos podem produzir proteases que apresentam maior habilidade de difusão no meio de cultura líquido o que já foi discutido anteriormente nos resultados de produção de lipase.

O presente estudo demostra o potencial dos fungos filamentosos isolados dos frutos da macaúba como produtores de enzimas, lipase e protease, de interesse biotecnológico. Sabe-se que uso de enzimas provinientes de fungos segundo Barata et al., (2007), oferecem uma vantagem em relação ao processo de purificação em relação à bacterias e leveduras, pois o micelio é facilmente removido por meio de filtração. Esta característica de fácil remoção do 
mícelio por meio de filtração contribui para o uso das enzimas provinientes de fungos encontradas no presente estudo no mercado biotecnológico.

Os isolados selecionados, por apresentarem maior atividade lipolítica e proteolítica, podem ser utilizados para estudos mais específicos, visando identificar as características de cada isolado, oferecendo assim condições de aumentar a sua produtividade (Andianarayana e Ellaih, 2002; Çalik et al., 2002).

\section{CONCLUSÃO}

Os resultados evidenciam o potencial dos fungos filamentosos isolados dos frutos da macaúba como produtores de lipases e proteases e adicionalmente contribuem para o estudo do beneficiamento e conservação do fruto, sendo que todos os morfotipos apresentaram resultado positivo para a secreção extracelular de protease e os morfotipos M62, M184 e M233 para a secreção extracelular de lipase. O uso da técnica de pré-seleção em meio sólido como forma de indicar fungos filamentosos produtores de lipase e proteases, mostrou-se insuficiente para a triagem da produção de lipase e protease dos morfotipos avaliados neste estudo, sendo necessário a realização de ensaios em meios de culturas líquidos para confirmação de produção de enzima extracelular e quantificação da atividade das mesmas. Os morfotipos em estudo estão sendo identificados no nível de espécie por meio de métodos moleculares e serão avaliados quanto ao potencial de produção de enzimas lipases em fermentação em estado sólido usando como substrato a torta da palmeira macaúba.

\section{REFERÊNCIAS}

ADINARAYANA, K.; ELLAIAK, P. Response surface optimization of the critical medium components for the production of alkaline protease by a newly isolated Bacillus sp. Journal of Pharmacy Pharmaceutical Science, Alberta, v. 5, n. 3, p. 272-278, 2002.

BARATA, R. A.; ANDRADE, M. H. G.; RODRIGUES, R. D.; CASTRO, I. M. Purification and characterization of an extracellular trypsina-like protease of Fusarium oxysporum var. lini. Journal of Bioscience and Bioengineering, v. 94, n. 4, p. 304-308, 2002.

CHARNEY, J. e TOMARELLI, R.M. A colorimetric method for the determination of the proteolytic activity of duodenal juice. Journal of Biological Chemistry, v. 23, p. 501-505, 1947.

COLEN, G., Isolamento e seleção de fungos filamentosos produtores de lipases. Tese (Doutorado em Ciência de Alimento). Universidade Federal de Minas Gerais, Belo Horizonte. 2006.

COLLA, L. M.; REINEHR, C. O.; COSTA, J. A. V. Aplicações e produção de lipases microbianas. Revista de Ciências Exatas Aplicadas e Tecnológicas da Universidade de Passo Fundo, vol.4, p. 1-14, 2012. 


\section{9 a 22 de outubro de 2014 \\ Florianópolis/SC}

ÇALIK, P.; BILIR, E.; ÇALIK, G.; OZDAMAR, T. H. Influence of $\mathrm{pH}$ conditions on metabolic regulations in serine alkaline protease production by Bacillus licheniformis. Enzyme and Microbial Technology, New York, v. 31, n. 5, p. 685-697, 2002.

FREIRE, D.M.A; CASTILHO, L.R. Lipases em biocatálise, produção, aplicações e mercado. Enzimas em biotecnologia. Editora Interciência, p. 506, 2008.

GUPTA, R.; BEG, Q.K.; LORENZ, P. Bacterial alkaline proteases: molecular approaches and industrial applications. Applied Microbiology Biotechnology, v.59, p. 15-32, 2002.

HASAN, F.; SHAH, A. A.; HAMEED, A. Industrial applications of microbial lipases. Enzyme and Microbial technology, v. 39, p. 235-251, 2006.

HOUDE, A., KADEMI, A., LEBLANC, D. Lipases and their industrial applications: an overview. Applied Biochemistry and Biotechnology-A Enzyme Engineering and Biotechnology, v. 118, n. 1-3, p. 155-170, 2004.

JAEGER, K. E., e EGGERT, T. Lipases for biotechnology. Current opinion in biotechnology, p.90-97, 2002.

LORENZI, H.; SOUZA, H.M.; COSTA, J.T.M.; CERQUEIRA, L.S.C.; FERREIRA, E. Palmeiras brasileiras e exóticas cultivadas. Nova odessa, São Paulo. Instituto Platarum, 2004.

PAPAGIANNI, M. Fungal morphology and metabolic production in submerged mycelia processes. Biotechnology Advances, v. 22, p. 189-259, 2004.

PÉREZ-DE-MORA, A; REUTER, B; LUCIO, M; AHNE, A; SCHLOTER, M; PRITSCH, K. Activity of native hydrolytic enzymes and their association with the cell wall of three ectomycorrhizal fungi. Mycorrhiza, v.23, p. 185-197, 2013.

ROMERO, F. J.; GARCÍA, L. A.; SALAS, J. A.; DÍAZ, M.; QUIRÓS, L. M. Production, purification and partial characterization of two extracellular proteases from Serratia marcescens grown in whey. Process Biochemistry, v. 36, p. 507-515, 2001.

SILVA, M. S., Atividade enzimática extracelular de leveduras isoladas da fermentaçãodo cacau. Dissertação (Mestrado em Biotecnologia). Universidade Estadual de Feira de Santana, p. $82,2011$.

SHARMA, R.; CHISTI, Y.; BANERJEE, Y. C. Production, purification, characterization and applications of lipases. Biotechnology Advances, v. 19, p. 627-662, 2001.

WINKLER, U.K. e M. STUCKMANN. Glycogen, hyaluronate, and some other polysaccharides greatly enhance the formation of exolipase by Serratia marcescens. Journal of Bacteriology, v.138, p. 663-670, 1979. 